\title{
Spatiotemporal evolution of ecosystem services in South China Karst and driving mechanism
}

\author{
Shihao ZHANG ${ }^{1}$ \\ ${ }^{1}$ Guizhou Normal University
}

February 20, 2021

\begin{abstract}
To explore the above-mentioned problems, we analyzed the spatiotemporal evolution of ES (WY, SC, NPP, nitrogen and phosphorus export, HQ, CS, and Bio) in SCK, and combined policy (GFG), natural factors (MP, MT, PET, and VC) and human activities (PD, NL, GDP, FL, Forest, Grass, BL and UL) discussed the driving forces of ES changes in different landscapes. The results showed that from 1982 to 2018, WY, nitrogen Export, HQ, CS and Bio in SCK showed a decreasing trend, while SC and NPP showed an increasing trend. WY had a large decrease in all ES, a decrease of 13.23\%; while NPP had a large increase, an increase of $19.16 \%$. Comparing different landscape, the study found that SC, NPP, nitrogen and phosphorus export, CS and Bio in non-karst were higher than in karst, while HQ was the opposite. This study showed that natural factors (MP, MT, PET and VC) are the main factors of affecting ES in SCK, and found that the driving factors of ES indicators in different landscapes (karst and non-karst) are not the same. The study emphasized mountain enclosure for afforestation in karst suitable forests and barren hills to restore ES; fast-growing and pioneer species with a large amount of fine roots were planted in wasteland and rocky desertification areas to increase soil conservation services in the early ecosystems; through the policy of migration and employment, the human disturbance to nature can be reduced and habitat quality and biodiversity service can be improved.
\end{abstract}

\section{Hosted file}

20210216.manuscript.pdf available at https://authorea.com/users/397006/articles/510049spatiotemporal-evolution-of-ecosystem-services-in-south-china-karst-and-drivingmechanism 